\section{Endoscopic ultrasound guided fine-needle aspiration without rapid on site evaluation by cytopathologist: An institutional experience}

\section{Sir,}

The adequacy rate and number of needle passes are the key determinant factors in endoscopic ultrasound guided fine-needle aspiration (EUS-FNA). Many studies have reported improved diagnostic yield by having rapid on site evaluation (ROSE) by a cytopathologist. ${ }^{[1,2]}$ However, a recent systemic review reported that ROSE is associated with an improvement in adequacy rates when implemented at sites where the per-case adequacy rate without ROSE is low. ${ }^{[3]}$ Another meta-analysis showed that ROSE is associated with a small, but statistically significant, improvement in adequacy rates. ${ }^{[4]}$ However, availability and cost effectiveness of ROSE by a cytopathologist has always been an issue, especially in developing countries like India. We have been doing EUS-FNA without ROSE at a high volume tertiary care center and we retrospectively analyzed our data from January 2013 to September 2014. A total of 226 patients with 242 solid lesions underwent EUS-FNA by a linear Olympus GF-UCT180 echoendoscope (Olympus America Inc., Center Valley, PA, USA) using a 22 gauge needle. During EUS-FNA procedure, we made 10-12 to-and-fro movements during each pass, did fanning and applied suction with a $10 \mathrm{ml}$ syringe for $2-4 \mathrm{~s}$. The slides were prepared by the resident after spreading material from the needle and reviewed by the gastroenterologist for gross appearance for presence of material. Half of the slides prepared were fixed with ethanol, and half were air dried. The site was lymph node in 122 lesions (50.4\%), pancreas in

\begin{tabular}{lcc}
\hline \multicolumn{3}{l}{ Table 1: Number of passes and sample adequacy of various } \\
lesions
\end{tabular}

84 lesions (34.4\%), liver in 14 lesions (5.8\%), subepithelial gastrointestinal tissue in $13(5.4 \%)$ and others (lung, biliary and adrenal) in 9 lesions (3.7\%).

The slides were sent to the pathology department and examined by the cytopathologist after staining. The sample was reported adequate if there were enough cells of the representative tissue to make a conclusive diagnosis of a benign or malignant pathology. If there were few abnormal cells suspicious of malignancy, the sample was considered adequate. Of a total 242 lesions sampled, 215 (88.8\%) were reported adequate and did not require a repeat EUS-FNA. The adequacy rate of lymph node lesions, which were the most common, was $90.9 \%$. Otherwise, the adequacy rate varied depending on the type of lesion [Table 1]. Furthermore, the mean number of passes was calculated for various lesions, and it was maximum for pancreatic lesions $(2.62 \pm 1.18)$, which are considered relatively hard lesions.

Our experience shows that, at high volume centers where an experienced gastroenterologist is available, performing a EUS-FNA even in the absence of ROSE yields acceptable results. It is not that all the studies using ROSE yielded better results. In a prospective multicenter study with 409 patients, two centers used ROSE and two did not. ${ }^{[5]}$ Results were similar in both groups, and merely differed in a higher negative predictive value in the subgroup of patients with extra intestinal mass lesions in the group with ROSE. Therefore, keeping in view the unavailability and cost constraints of onsite pathologist, higher results can be obtained by better gross examination of the slides by the gastroenterologist.

\section{Sandeep Nijhawan, Bir Singh, Kumar Shwetanshu Narayan, Dilip Ramrakhiani ${ }^{1}$}

\author{
Departments of Gastroenterology and ${ }^{1}$ Pathology, SMS Medical \\ College, Jaipur, Rajasthan, India \\ Address for correspondence: Dr. Sandeep Nijhawan, \\ Department of Gastroenterology, \\ SMS Medical College, Jaipur - 302 004, Rajasthan, India. \\ E-mail: dr_nijhawan@yahoo.com
}

\section{References}

1. Ecka RS, Sharma M. Rapid on-site evaluation of EUS-FNA by cytopathologist: An experience of a tertiary hospital. Diagn Cytopathol 2013;41:1075-80.

2. Klapman JB, Logrono R, Dye CE, Waxman I. Clinical impact of on-site cytopathology interpretation on endoscopic ultrasound-guided fine needle aspiration. Am J Gastroenterol 2003;98:1289-94.

3. Schmidt RL, Witt BL, Matynia AP, Barraza G, Layfield LJ, Adler DG. Rapid on-site evaluation increases endoscopic ultrasound-guided 
fine-needle aspiration adequacy for pancreatic lesions. Dig Dis Sci 2013;58:872-82.

4. Matynia AP, Schmidt RL, Barraza G, Layfield LJ, Siddiqui AA, Adler DG. Impact of rapid on-site evaluation on the adequacy of endoscopic-ultrasound guided fine-needle aspiration of solid pancreatic lesions: A systematic review and meta-analysis. J Gastroenterol Hepatol 2014;29:697-705.

5. Wiersema MJ, Vilmann P, Giovannini M, Chang KJ, Wiersema LM. Endosonography-guided fine-needle aspiration biopsy: Diagnostic accuracy and complication assessment. Gastroenterology 1997;112:1087-95.
Access this article online

\section{Website:}

www.jdeonline.in

DOI:

$10.4103 / 0976-5042.155253$
Quick Response Code

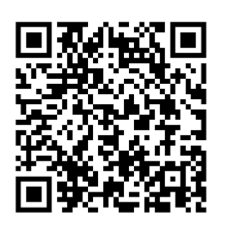

